\title{
People with dementia and carers online discussing surveillance
}

\author{
VERMEER, Yvette ${ }^{\text {a1 }}$; HIGGS, Paul ${ }^{\mathrm{a} 2}$; CHARLESWORTH, Georgina ${ }^{\mathrm{b} 3}$ \\ a UCL, Faculty of Brain Sciences, Division of Psychiatry, Maple House,6th Floor,149 Tottenham Court Rd, London \\ W1T 7NF, United Kingdom \\ ${ }^{b}$ UCL, Faculty of Brain Sciences, Department for Clinical, Education, and Health Psychology, 1-19 Torrington \\ Place, London, WC1E 7HB, United Kingdom \\ ${ }^{1}$ Yvette Vermeer, y.vermeer@ucl.ac.uk, Early Stage Researcher, \\ ${ }^{2}$ Paul Higgs, p.higgs@ucl.ac.uk, Professor. \\ ${ }^{3}$ Georgina Charlesworth, G.charlesworth@ucl.ac.uk, Associate Professor, \\ Interdisciplinary Network for Dementia Using Current Technology (INDUCT)
}

\begin{abstract}
:
Purpose - To interrogate online comments from consumers with dementia and family carers on surveillance technology products used by or for people with dementia

Design/methodology/approach - A naturalistic, observational study of qualitative posts $(N=120)$ by people with dementia $(n=7)$ and family carers $(n=38)$ to discussion threads on surveillance technology (ST), hosted by an online dementia support forum in the Netherlands. Kozinet's (2002) typology was used to describe respondent characteristics, and comments on features of ST products were analysed within a pre-existing framework.
\end{abstract}

Findings - Forum users were mainly 'tourists' interested in ST, with some 'insiders' interested in sharing experiences of ST use. They expressed a lack of trust in information from marketers and providers do to the experience of being provided with poor information. Consumer to consumer comments on products triangulated with previous face-to-face qualitative studies. Carers prioritised 'peace of mind' through location monitoring. In contrast, people with dementia prioritised user-friendliness (simple, with capability and compatible with daily routines).

Implication/value - Utilising online discussions of ST products provides a rapid approach to understanding current consumer needs and preferences in the ever-changing world of technology.

Originality - No previous study is known to have explored the views of carers as well as people with dementia in online discussions about ST.

Keywords - surveillance technology, people living with dementia, family carers, needs, online discussions, netnography 


\section{Introduction}

Dementia has become a major concern and in 2015 worldwide costs were estimated at US\$818 billion (Wimo et al.,2017). In Europe, dementia is identified as a societal challenge, and the necessity for research on technology-related care has been highlighted (European Commission, 2015; European Parliament, 2011). Social policies and market priorities seek to facilitate 'ageing in place' through the use of technology (Kubitschke et al., 2010; van Hoof et al., 2010) which is thought to delay institutionalisation; encourage older adults to remain in their own home in later life (Brittain et al., 2010); to save costs (Duff and Dolphin, 2007) and to reduce family carer burden (McHugh et al., 2012). Best practice guidance on technology and dementia has recently been made available from the European Union on www.dementiainduct.eu/guidance/ (INDUCT, 2019) with extensive recommendations for developers, designers, policy-makers, researchers and care-providers on how to design, implement and evaluate products. However, it is known that users of technology often take matters 'into their own hands' to adapt, personalise and customise, for example through combining household items with technological devices (Greenhalgh et al., 2013; Gibson et al., 2019; Vermeer et al., 2019a). 'Bricolage' highlights the creativity of individuals, the limitations of commercially available products and the potential for consumer to consumer sharing of experience and 'know-how'.

\section{Independence and technology}

Many people diagnosed with dementia wish to retain their independence outside the home whilst having the security of knowing that they will be found if lost. In addition, family carers like to feel reassured that the person with dementia is safe, even if they are away from home. Thus, people with dementia and their carers represent a market for technologies such as Global Positioning Systems (GPS) trackers and alarms. There has been much discussion on the 
most appropriate terminology for such technology, and trackers have been classified variously as 'information and communication technology', 'assistive or enabling technology' or 'surveillance technology'. Although the word 'surveillance' has negative connotations and ethical implications, it is an accurate descriptor of the monitoring products on sale, some of which are barely modified from their original form used for tracking dogs, children or prisoners (for discussion see Vermeer, Charlesworth and Higgs 2019a). The term 'surveillance' also reflects the covert use of tracking products, for example on people with dementia who do not have the capacity to consent to the use of wearable devices and for whom a 'best interest' decision is made to reduce the risks associated with unmonitored 'wandering'. In a recent review of needs of people with dementia and family carers in relation to surveillance technology (ST), 28 eligible studies were identified (Vermeer et al., 2019b). Most of the included studies reported the carers' perspective with the predominant themes being location accuracy and increasing the safety of the person with dementia. Where the voice of the person with dementia was included, it was to express the need for simple but useful technology that fits within their capacity and existing routines.

\section{The user's voice online}

The promotion of policies based on notions of 'active ageing' leads to an emphasis on autonomy (Lopez,2015), yet everyday technologies such as smart phones and tablet computers can be perceived as challenging by people with dementia (Wallcook et al., 2019), and even 'commonplace' technologies such as microwaves and televisions are used less over time due to declining abilities (Malinowsky et al., 2010; Nygård et al., 2012; Wallcook et al., 2019). Understanding how carers and people with dementia perceive and use technology both inside and away from the home will help developers, marketers and care practitioners 
respectively to produce, market and provide appropriate products. Researchers and developers are urged to involve people with dementia to collect their views (DEEP, 2013), especially considering that they might not have a wish for ST (Greenhalgh et al., 2013; Neven, 2010). The voice of the person with dementia is increasingly heard online, using platforms such as blogs, Facebook and Twitter (Kenigsberg, et al., 2017; Craig and Strivens, 2016; Talbot et al., 2020). As a wide range of tracking devices are available online in 'direct to consumer' outlets (Rialle et al., 2008; Robinson et al., 2009; Vermeer et al., 2019c; Wan et al., 2016), online discussion forums are likely to be an ideal setting from which to gather consumer views of products and to observe 'consumer to consumer' discussion on which products best meet their needs. Indeed, it has been argued that the internet is an appropriate and rich way to understand public health issues and individual user needs (Keeling et al., 2013; Jamison et al., 2018; Newman et al., 2019). People can voluntarily decide to post in the threads that they are interested in, resulting in insights that may go be beyond the reach of interviews (Jamison et al., 2018). In particular, online communities engage, discuss and inform their purchasing activities and give more open insights into consumers' needs, wants and choices compared to traditional research methods because of anonymity (Taylor and Bogdan, 1984; Childress and Asamen, 1998; Kozinets, 2002, Xun and Reynolds, 2010). Consumers use forums as a tool where they gather information before making a purchase (Adjej et al., 2010) and information created within forums can have a greater influence on consumer's decision-making than 'offline' word-of-mouth (Steffes and Burgee, 2009). Service providers can use online consumer input to inform service improvements (Keeling et al., 2013) and the analysis of respondent involvement within a forum can serve as crucial input for marketing research (Kozinets, 2002). Accordingly, online forums are seen as "goldmines of information" (Childress and Asamen, 1998; Xun and Reynolds, 2010). 
A popular method for studying naturally-occurring engagement with online forums has been the use of 'netnography' (Kozinet, 2002). Indeed, a recent review 'netnographic studies' of customer behaviour online identified as many as 321 studies published in marketing journals in the two decades between 1997 and 2017 (Heinonen and Medberg 2018). The term 'netnography' refers to the application of the philosophy of ethnography to the computed online environment to better understand consumers (Kozinet, 2002). The advantages are that it uses publicly available information, is less obtrusive and time-consuming than interviews and focus groups, and provides insights in naturally occurring behaviours on how consumers search for, and share, information, opinions, and experiences. There has been recent interest in applying netnography to online activities of people with dementia (Conger et al., 2019; Thomas, 2017), However, there are, as yet, no published studies of engagement of people with dementia with online discussion of ST.

In sum, 'offline' research exists on user-needs for ST, but online research is only just beginning. Gathering the online views of people with dementia and their supporters could provide new insights. The objective of this study is to examine in-depth what carers and, separately, people with dementia (1) recommend and (2) need in ST design as discussed on an online forum.

Research question: "What do consumers with dementia and family carers state, ask and discuss when interacting with an online forum on the consumption of ST for people with dementia?"

\section{Methods}

\section{Design}


This naturalistic, netnographic study involved gathering qualitative comments from the Alzheimer Nederland online forum, in particular from discussion threads dedicated to ST for carers and people living with dementia at home. Descriptive data about the forum was also gathered from the archived history of activities.

\section{Setting}

Alzheimer Nederland provide a Dutch-language online forum dedicated to providing information on dementia. The forum is a source through which carers and people with dementia can search and/or offer information and support. The page "dealing with dementia at home" was started by the forum moderator in 2014 and, according to the Google Analytic “Page views" measure (Pakkala et al., 2012), had over 45,000 views from April to August 2018. Within this page there were two threads on ST: (1) "Surveillance technologies to follow someone with dementia" started by the forum moderator in January 2014 (viewed 34636 times by $3^{\text {rd }}$ September 2018) and (2) "Surveillance and wandering technologies to prevent people getting lost" also started by the forum moderator, this time in July 2015 (viewed 99223 times by September 2018). Alzheimer Nederland noticed that, besides a growth in popularity of the existing threads, they received additional enquiries about ST. In collaboration with the first author, an additional thread "How do you find the best surveillance technologies?" was posted in April 2018. By September 2018 it had viewing figures of 2516.

\section{Participants}


In order to post on the forum, members were required to register, accept the disclosure page and indicate their role (i.e. researcher, student, carer, or person living with dementia). Members that responded to posts (henceforth termed "respondents") were identified by usernames and role descriptions linked to each of the selected posts. Other characteristics (e.g. gender, year of birth) were not retrieved as not every respondent chose to display this to the public.

\section{Eligibility criteria}

Eligible respondents and their comments were included if they met the following criteria: (1) identified themselves other than a researcher, student, or forum moderator (2) wrote diligently and understandably in Dutch. As such, comments from forum moderators, students and researchers were excluded.

\section{Ethics}

Alzheimer Nederland gave permission to use the data for research purposes before data were collected. This was consulted with the Law of Medical-Scientific Research committee and deemed unnecessary for a formal procedure due to the non-medical nature of the research and the precautions taken (CCMO, 2001). In adherence with the Dutch law regarding protection of personal data (Wet Bescherming Persoonsgegevens), the website's disclosure page provided information about this study by referring to the information booklet. Respondents were made aware that by clicking "agree" and posting on the forum, their responses were available to the public. By clicking on "agree" respondents consented that 
their comments could be used anonymously. If respondents had any questions, they could contact the researchers using the email addresses or telephone numbers provided in the information booklet. Further, precautions were taken to protect the identity of participants by anonymization of names and places and translating the comments into English.

\section{Data analysis}

Thread comments posted between $20^{\text {th }}$ January 2014 to $7^{\text {th }}$ July 2018 were extracted over a four month period in the summer of 2018. The comments copied to Word and read through in Dutch before for translation into English and transfer into NVivo 12 by the first author. Content analysis included counting frequently mentioned words, excluding stop words, and categorising key topics discussed on the forum. Qualitative data on products was organised according to a framework of features initially developed in a systematic review of the needs of people with dementia and their family supporters for ST products (Vermeer et al., 2019b). The framework consists of 6 categories each of which contains a number of items namely effect (safety, independence, confidence, 'peace of mind' and free-time), product characteristics (price, size, weight, SOS button, one technology), user-friendly (simple to use, but useful, capacity, routine), user-context (acceptance, navigation, locate accurately, notifications, reliable, communication), privacy (privacy data, safety risk zones, legal and liability) and design details (battery, simplicity, aesthetics, reinforcements). The second author double-coded a subset of each dataset and discussed any discrepancies until resolved. Further, risk of interpretation bias was minimized by ensuring that the paraphrasing of quotes in English reflected the original Dutch comments as closely as possible. Queries arising from this process were resolved through discussions between the authors. 
Finally, respondent characteristics were classified according to Kozinet's (2002) typology of "tourists" (which this study defined as respondents who placed fewer than three posts on the overall forum), "minglers" (remained on the forum for 6-12 months, showed strong social associations but minimum consideration for the consumption activity, which this study defined as those who posted between three and 50 messages,), "devotees" (focused on the consumption activity without interested in the social aspect and this study added that they should have placed over 50 posts on the overall forum) and "insiders" (long-standing respondents with interested in the social aspect of the forum as well as the consumption activity and who also posted over 50 posts on the overall forum. The Google Analytic "Page views" measure was used to generate data on page views (Pakkala et al., 2012).

\section{Results}

In total, 120 eligible comments from a total of 45 distinct respondents ( 38 carers and 7 people with dementia), posted over the 3 'surveillance technology' threads within the online forum. The most popular thread concerned 'technologies to prevent people getting lost' which attracted 28 respondents. Threads on 'ST for following' and 'finding the best ST' attracted 15 and 8 respondents respectively. An additional five comments were excluded as they were not from respondents identifying either as people with dementia or family carers. In terms of Kozinet's classifications, the prevailing respondent category was 'tourist' (table 1) indicating a lack of interaction between forum members. In addition, there were both carers and people with dementia who met the criteria of 'insiders', that is respondents who were not only very active on the overall forum but also sharing their experiences of ST. No respondents met the 
criteria for 'mingler' or 'devotee' and there were a small number of respondents who posted between 2 and 50 messages in the overall forum, but did not continue to follow the ST thread.

Table 1: Number of respondents in each of three threads on the Alzheimer Nederland forum discussing surveillance technology.

\begin{tabular}{|c|c|c|c|}
\hline \multirow{2}{*}{$\begin{array}{l}\text { Number of respondents } \\
\text { within each thread }\end{array}$} & \multicolumn{3}{|c|}{ Thread } \\
\hline & ST for prevention & ST for following & Finding the best ST \\
\hline Carers & 24 & 12 & 6 \\
\hline 'Insiders' & 2 & 3 & 2 \\
\hline 'Tourists' & 15 & 6 & 3 \\
\hline Other & 7 & 3 & 1 \\
\hline People with dementia & 4 & 3 & 2 \\
\hline 'Insiders' & 1 & 1 & 1 \\
\hline 'Tourists' & 3 & 1 & 1 \\
\hline Other & - & 1 & - \\
\hline
\end{tabular}

*Three carers and one person with dementia (all 'insiders') posted comments in more than one thread.

Looking at the content of posts, the most frequent words mentioned were: 1 ) watch (as in a timepiece worn on wrist), 2) GPS, 3) technology device, 4) “Finder", 5) app, 6) phone, 7) "Drugstore" and 8) track. The "Finder" is a pseudonym for a brand that sells devices which includes a GPS tracker and a SOS-button. It can be connected to an online account where the carer can track the location of the person wearing the device, from their tablet, or mobile phone. "Drugstore" is a pseudonym for a well-known retailer that sold the Finder in-store and predominantly online.

Key topics discussed on the forum were (1) providers of devices and services (72 mentions across 3 threads) (2) surveillance technology products (55 mentions across 3 threads) (3) questions about user experience (13 mentions across 3 threads) and (4) comments on people with dementia wandering, going missing or getting lost (13 mentions across 2 threads) .

(1) Providers 
Respondents discussed providers by recounting their experience with informing and purchasing certain ST. This was often followed by comments about the level of (mis)trust regarding providers. Respondents did not trust websites perceived as "messy" and or where it was difficult to contact the provider.

"I know the site of the "Carebelt" but it is messy and doesn't make me trust their service and support" (carer)

Strikingly, many respondents did not know where to buy ST, or what is available on the (online) market. A few carers even mentioned that there is a low supply on the market.

"it's kind a weird that the industry doesn't respond to the increasing number of people having dementia" (carer)

Only one respondent mentioned purchasing ST in a physical store.

"Great products, a bit commercialised. In the beginning of my dementia, we made several purchases at various care stores. Purchases advised by healthcare professionals or if we thought that a product might actually help. Looking back, it costed us more money than that it actually benefitted us." (Person with dementia)

(2) Products

The main products under discussion were "Finder" (see above) and "Carebelt" (a pseudonym for another frequently mentioned brand who also market a device similar to "Finder"). The first comments on the forum described the "Finder" and "Carebelt", and these continued to 
be the most discussed ST across the forum. In addition, many respondents gave general descriptions of a "watch" and few mentioned brand names. Respondents tended to ask others about their experiences or recommendations rather than describing their own, but there were examples of respondents recommending brands, or trying to dissuade others from making purchases. Whether users' recommendations were followed by other forum users is not known. Table 2 illustrates the coverage of the online discussions on features and items identified in the systematic review of 28 offline qualitative studies (Vermeer et al 2019b). 
Table 2. Content of posts about products on the online threads about surveillance technology, organised within Vermeer, Higgs and Charlesworth (2019b) framework

\begin{tabular}{|c|c|c|c|}
\hline Features & Items & Threads & Mentions \\
\hline \multirow{6}{*}{ Effect } & & 3 & 15 \\
\hline & Safety & 1 & 1 \\
\hline & Independence & 1 & 1 \\
\hline & Confidence & 1 & 1 \\
\hline & Peace of mind & 3 & 12 \\
\hline & Free time & 0 & 0 \\
\hline \multirow[t]{6}{*}{ Product Characteristics } & & 3 & 37 \\
\hline & Price & 3 & 15 \\
\hline & Size and weight & 3 & 5 \\
\hline & SOS-button & 3 & 11 \\
\hline & One technology & 1 & 2 \\
\hline & ${ }^{*}$ Clock & 2 & 4 \\
\hline \multirow[t]{5}{*}{ User-friendliness } & & 3 & 57 \\
\hline & Simple to use & 3 & 7 \\
\hline & Useful & 2 & 9 \\
\hline & Capacity & 2 & 14 \\
\hline & Routine & 3 & 21 \\
\hline \multirow[t]{7}{*}{ User-context } & & 3 & 65 \\
\hline & Acceptance & 2 & 2 \\
\hline & Navigation & 1 & 3 \\
\hline & Locate accurately & 3 & 23 \\
\hline & Notifications & 3 & 10 \\
\hline & Reliable & 3 & 10 \\
\hline & Communication & 2 & 17 \\
\hline \multirow[t]{6}{*}{ Privacy } & & 2 & 12 \\
\hline & Privacy data & 1 & 2 \\
\hline & Safety and risk & 1 & 3 \\
\hline & zones & 2 & 2 \\
\hline & *Autonomy & 1 & 3 \\
\hline & Legal and liability & 1 & 2 \\
\hline \multirow[t]{5}{*}{ Design details } & & 3 & 34 \\
\hline & Battery & 3 & 16 \\
\hline & Simplicity & 3 & 8 \\
\hline & Aesthetics & 2 & 3 \\
\hline & Reinforcements & 2 & 6 \\
\hline
\end{tabular}

*Additional items not included in the Vermeer et al., (2019b) framework. 
Effect

The most commonly mentioned effect of using ST products was "peace of mind".

"ST is not only to prevent him getting lost ... for everyone's peace of mind" (carer)

"If I feel like she is wandering off for a long time, I can directly locate her position" (carer)

"It [ST] gives you a feeling of safety, because he has been lost for two days and a night and that experience was no good for anyone" (carer)

However, the contention that ST products increase safety was disputed. For example, the following exchange took place in the thread "wandering technologies to prevent people getting lost":

"This morning I saw a sign that stated 'ST prevents wandering with dementia". This statement hit me... Even though my mom didn't wander because my dad did all he could to take care of her, ST of course does not prevent wandering. That statement isn't right and that's also what I think of the title of this thread" (carer)

"Of course you're right! ST cannot "prevent" wandering. I can imagine that you found that text misleading and offending. ST "can" help give the family of a person-with-early-dementia peace of mind, or to locate someone who is lost. Actually ST has an "expiry date". There are risks attached." (carer 2) 


\section{Product characteristics}

The most often mentioned item within product characteristics was price. Carers paid or were willing to pay between 50 and 70 euro for STs. Some mentioned how they disliked paying a monthly fee. Others even warned of additional costs that may occur when ordering from abroad or online. Only one person with dementia mentioned costs.

The second most commonly mentioned aspect of product characteristics concerned SOS buttons which carers described as beneficial. However, some commented that it should be large enough to press.

"the SOS-button from "Finder" is larger so that's easier" (carer)

The size of product received a small number of mentions, with carers describing a preference for a small sized product, often with descriptions indicative of covert use.

"It's about 5 to $4 \mathrm{~cm}$, we put it in her wallet...she doesn't know that" (carer)

A theme emerged when both carers and people with dementia described that tracking watches should have a familiar display time with a clock face, or dial.

"The good thing is that it's a watch and hopefully my mother in law carries it (always) with her" (Finder - carer 2)

"After a lot of fuss, he uses it. He had trouble saying goodbye to his familiar watch" (Finder-carer 3)

User-friendly 
All items within 'user-friendly' were frequently mentioned, and this was especially apparent in the comments of people with dementia. Both carers and people with dementia liked products that require little skill.

"the most important thing as someone with dementia is that you don't get all these undertakings and you lose a loooooot of things, especially your phone, or watch. My advice keep it as easy and simple as possible" (Finder person with dementia)

If a product was difficult to use, carers thought that guiding instructions should be provided. "It didn't come with a guideline... but I liked that I could use it intuitively" (Finder carer)

"Important: for its followers (including my elderly mother) it should be easy to use" (Carer)

In contrast, people with dementia stressed that what might be considered simple by some could be difficult for others. Consequently, many people with dementia and some carers expressed that STs are just not designed for dementia.

"Most products are not conceptualized by people without dementia. But they do get their insights from professional carers. However I had to work with it or learn how to use it. My spouse did understand it and was able to explain it. But me as someone with dementia has difficulties with operating or understanding the product. With some doubts we bought it anyway" (Person living with dementia)

"The product is just not designed for people with dementia" (Finder- carer) 
References were also made about the stage of the disease. Some carers described how they were no longer able to use ST due to the person with dementia being "too far gone". Some carers recommended that ST should be adaptable for advancing impairment. Others thought that a solution would be to teach people with early-stage dementia to use ST. Yet others thought teaching "new" things would be impossible. One person with dementia commented:

"There are many products you won't be able to use due to the progression (Not one salesperson pointed this out btw). Then quickly there will be irritation, spouse being impatient and this following pressure makes me just even more insecure and angry. They're like hello this costed us a lot of money and you said you wanted this as well" (person with dementia)

Respondents need a product that fits within the daily routines of those involved. Emphasis was on how products should be easily integrated into day-to-day tasks.

"I wear it around my neck or under my sweater, every night when going to bed I charge it" (Finder - person with dementia)

"My dad is used to taking off his watch every night (put it in the charger) and wear it in the morning which has been a habit for years [...]. Finder is something new. New things which are often difficult to learn for older adults (not trying to be mean) that is why I choose this solution. Everybody has their own choice" (Finder - carer)

\section{User-context}

In the three threads, a pre-dominant theme for carers was user-context. They discussed how the person with dementia would use ST. However, most discussed how the person with 
dementia would not have the capacity to use ST. There were no descriptions of needing ST that provides navigation and gives directions to the person with dementia. Instead, carers stressed the need to locate someone accurately. Some carers explained they want to locate someone by seeing their historical route taken. When carers reviewed ST negatively it was often because the product could not locate someone in or outside of buildings.

"If my dad's inside we get to see this whole bunch of streets... the last time he went inside somewhere we had to call the police" (Watch - carer)

Carers would recommend how their product would notify them if something happened. They also wrote their need for a reliable product that loads with speed and has minimum technical problems.

"For others who are still looking, I came across a nice watch [...] It has a SOSbutton and via the app on your mobile you can log in and: 1. Determine and follow the location 2. See the route travelled 3. Set a "geofence" and if the person leaves this you will receive a notification 4. You can call the watch" (Watch - carer)

Few carers mentioned that they wanted the person with dementia to accept the product, which according to them would happen by using familiar products (e.g. watches or bracelets). Carers also described how there could be some resistance by the person with dementia. Further, carers and people with dementia liked being able to communicate with each other through ST.

"Being able to communicate from a distance is perfect" (Finder - person living with dementia) 
Privacy

There was less discussion about privacy. Carers described how other family members would have access to the ST "to see where mom is to help out". Few carers raised questions about who would have access to the data generated by ST. However, these questions remained unanswered. Only a couple raised legal and liability issues surrounding ST and that the privacy of a person with dementia should be respected.

\section{Design details}

On occasion there was discussion about design-details. When this occurred, respondents would mainly discuss the (charging of) battery. In particular, carers would outline how they would run out of battery quickly. A minority even mentioned the number of days they would want the battery to last and how much they were willing to pay for a battery-life of over a year. A few carers' stressed they want to see how much percentage of the battery is left and to receive a notification when it is almost empty. Scarcely any contributors discussed the simplicity or visibility of ST designs. Only one carer mentioned that a product should be waterproof and three others commented on aesthetics. In keeping with the spirit of bricolage, respondents expressed their liking for products that could be adapted and personalised to fit their need, for example attachments for the product, and methods to attach the product to the person with dementia.

\section{Discussion}


This is the first study to our knowledge that retrieved insights from an online forum where carers and people with dementia shared their experience of, and questions about, wearable surveillance technology (ST) products designed for use outside of the home. Respondents were predominantly carers, but the independent and authentic voice of people with dementia was also present. The findings reinforce and extend existing knowledge on the differing needs and preferences of people with dementia and family carers. Whereas people with dementia focused mainly on user-friendliness of products, carers prioritised location accuracy for their peace of mind.

The four key topics raised by respondents in the ST discussion threads were: providers, products, questions about user experience, and stories of wandering or being lost. Forum discussion demonstrated brand awareness, possibly boosted by one of the providers running an advertising for one of the products during the course of these discussions, but also an erroneous belief that there was a lack of availability of ST products. The posts on products covered all six features of an existing framework previously generated to synthesise findings from a systematic review of 28 studies of ST in dementia (Vermeer et al., 2019b). Online discussion forums can serve as peer support given their accessibility for carers and people with dementia who feel isolated or lonely (McKeckie et al., 2014; Craig and Strivens, 2016). However, the type of information being shared on the forum was focused on raising questions before purchase or making recommendations about different STs.

Consumer to consumer contributions to the forum provided data on a greater range of product features and items than any one of the 28 studies in the Vermeer and colleagues (2019b) review indicating the value of gathering data from online forums. The replication of findings from earlier 'offline' studies suggests that online forums as a source of consumer 
views are a feasible alternative to qualitative interviews or focus groups, as previously concluded in comparisons of online forum versus offline interview data-collection (Jamieson et al., 2018). There were, however, differences in emphasis when comparing findings from this online study with previous literature. As might be expected, the consumer to consumer communication in the online forum had greater focus on providers and brands than could be reported in academic research. A second contrast was the difference in positioning in the role of ST in maintaining the safety of the person with dementia. The theme of safety was reported in 13 of 28 studies in Vermeer and colleagues review (2019b) with a number of studies accepting the marketing position that ST increases safety. However, neither safety nor independence were strongly represented in the online threads. Indeed, one carer disputed the contention that ST reduces risk. Within the forum threads, ST was primarily recommended for carers' peace of mind. Thirdly, design details, which have been major themes in previous ST research (McCabe and Innes 2013; Rahimi et al. 2007; Robinson et al., 2009) were hardly discussed. An exception to this was consideration of the battery as this was seen as vital to the reliability of the device and thus peace of mind.

\section{Strengths and Limitations}

A strength of this study is that the voice of the person with dementia is included, as are the voices of adults supporting parents. Much of the previous research, on ST has involved spouse carers (Vermeer et al., 2019b).

Qualitative studies on forums are strong and trustworthy when accompanied a structured framework informed by previous literature (Jamison et al., 2018) as was the case here. In this research, the framework of features and items from Vermeer and colleagues (2019b) review 
was used when considering the content of online postings about surveillance products. However, applying the framework in this way also revealed its limitations. As with any structure for categorising information, challenges arise when cross-category coding is required, such as the carer who commented on their 'cost-benefit' analysis of price and function.

"It cost us 130 Euro but we did it as the battery life was 30 days"

A challenge for the interpretation of data from online forums is the potential for an 'echo chamber' effect where the prevailing views from early in a thread are not merely repeated but amplified by later contributors. In the way that the 'loudest voices' might influence focus groups, early contributors to online discussion may unduly influence those joining in at a later point (Steffes and Burgee 2009; Newman et al., 2019). Online platforms also have the potential to transmit and perpetuate unhelpful stereotypes (Newman et al., 2019).

Using the Kozinet (2002) typology of respondent engagement with the forum, 'tourists' and 'insiders' were identified, but not 'minglers' or 'devotees'. With its focus on the consumer experience of purchasing and using ST, the potential 'emotional support' element of peer support may have been missed in the analysis as may examples of interactions and symbolic meaning which can be the focus of netnographic analyses (Kozinet, 2002). It was noted that tourists to this forum took on the role of "consumers" rather than peer supporters and did not react directly to other's personal experiences, or indeed comment on the way in which they had used any insights gained from their readings of others' posts. A handful of 'insiders' were actively sharing their experiences of ST, but again with a 'consumer' focus on recommended brands, or 'know how' on product use. A minority of respondents fell outside the Kozinets typology (designated 'other' in table 1). There is much debate in current research 
about ways to term or classify respondents. For example, Pongsakornrungsilp (2010) draws distinctions according to the level of engagement and intensity of resources invested by respondent (e.g. time, experience, knowledge).

Limitations for the study include: data extraction from one forum only; use of demeaning words and technical language such as "wandering" and "technology" respectively (selected by the moderator prior to the involvement of the researchers); the self-selecting nature of the sample, and the potential ambiguity of some comments when the 'tone of voice' cannot be heard. Some of the 5 comments deleted from the dataset were excluded due to the impression that the comment was sarcastic rather than genuine. Nevertheless, anonymity also carries a strength as respondents may feel safer, more comfortable, and more willing to share their views. Whilst Kozinet's 'member check' method was used to characterise forum users, a 'deeper dive' could have been taken into the qualitative data, for example by interpreting interactions and exploring symbolic meanings to provide additional insights.

\section{Implications for designers and researchers}

Two assumptions were apparent in the online data. First, carers are the main user and ST should be designed for them and second, people with dementia are unable to use ST. Potential conflicts between the interests and expectations of carers and persons with dementia have been noted previously. For example, Boman, Nygård and Rosenberg (2014) pointed out that 'significant others' often have worries about the person with dementia and therefore wish to use technology to monitor from afar. However, the implicit assumption that technologies that help carers will also be beneficial for the person with dementia does not necessarily hold true. Technological solutions can challenge the self-determination and sense of freedom of the 
person with dementia (Boman et al., 2014). This is, however, a point of individual difference as some people with dementia find renewed freedom and independence in travel with the reassurance of knowing that they can, if needed, be located through an application on their smartwatch (Vermeer et al., 2019a).

Descriptions of the 'bricolage' approach of adaptation to, and tinkering with, commercially available products provides further evidence of a mismatch between ST designs and consumer needs. "New innovations" need to be critically reflected in order to produce meaningful usercentred technology which improves daily-life enabling arrangements and effectively support caregiving (Puig de la Bellacase., 2012; Lopez., 2015). The findings suggest that this can be achieved when ST is person-centred and adaptable. The development of ST may have to be limited in order to make it useful for individuals in the different stages of dementia (McCabe and Innes., 2013; Meiland et al., 2012). However, the focus of development could also be on empowering people in regard to their personal strengths and abilities, rather than focussing solely on deficits (Huber et al., 2011).

Questions remain as to whether participants in the online forum make use of the consumer to consumer knowledge that they have gained. Future studies should seek to better understand the impact of engagement with forums. In addition, studies should be carried out in other countries and cultures so that comparisons can be drawn, and further involvement from people living with dementia is needed. Given the speed of development of technology, frequent updates are required, and online forums provide rapid access to consumer views.

\section{Implications for practice}


Practitioners in dementia services should be aware of the availability of products online and the limitations of the product descriptions and specifications. Organisations that support people with dementia may wish to review the information that they have available to signpost service users to ST. They should be aware of whether their organisation is in a position to endorse products freely or within a restricted range of locally commissioned devices. Any suggestions provided should take into account individual needs and preferences, bearing in mind that people with dementia commonly express a preference for technology that is simple to use, within one's capacity and compatible with existing daily routines (Robinson et al., 2007; Malinowsky et al., 2010; Nygård et al., 2012; Lopez, 2015; Wallcook et al., 2019). Manufacturers and marketers information does not necessarily provide the information that service users/ consumers need to make a decision on which device would best suit their needs at the time of purchase or in a future, considering that a person with dementia's navigational abilities might decline at a different rate to their physical mobility. Practitioners may wish to signpost to device-loaning services or retail outlets where devices can be handled prior to purchasing. Practitioners should also consider ethical and legal issues such as potential deprivation of liberty especially as such discussions were notable by their absence in the online forum.

\section{Conclusions}

Technology as part of healthcare delivery for people living with dementia is expected to grow (Scholz, 2016; WHO, 2012). Recognizing the ST needs of carers and people with dementia is important. People with dementia and family carers use online forums as a source of information for their purchasing decisions. Gathering data from online forums enriches 
findings from 'offline' methodologies. Forum posts reveal a lack of trust in providers and marketers due to poor provision of information. When designing or prescribing technologies, ST developers and health or social care professionals should take into account the potentially differing needs from carers and people with dementia, and their changing needs over time.

\section{Conflict of interest}

The author(s) declared no potential conflicts of interest with respect to the research, authorship and/or publication of this article.

\section{Funding}

The author(s) disclosed receipt of the following financial support for the research, authorship, and/or publication of this article: The research presented in this report/paper/deliverable was carried out as part of the Marie Curie Innovative Training Network (ITN) action, H2020-MSCAITN-2015, under grant agreement number 676265.

\section{Guarantor}

YV

\section{Acknowledgements}


The authors would like to thank Alzheimer Netherlands and the respondents who made the online forum discussion possible as well as the researchers from the Interdisciplinary Network for Dementia Using Current Technology (INDUCT) for their kindness and helpfulness in providing the information used in this work.

\section{Footnote}

We acknowledge that words such as wandering might be stigmatising; however, this is what respondents wrote on the forum.

\section{References}

Adjei, M.T., Noble, S.M. and Noble, C.H. (2010), "The influence of C2C communications in online brand communities on customer purchase behavior". Journal of the Academy of Marketing Science. Vol. 38, No 5, pp. 634-653

Alzheimer Netherlands (2017), "Forum Alzheimer Nederland". Available at http://forum.alzheimer-nederland.nl/ucp.php?mode=terms (Accessed: May 08, 2017).

Boman, I. L., Nygård, L., and Rosenberg, L. (2014), "Users' and professionals' contributions in the process of designing an easy-to-use videophone for people with dementia". Disability and Rehabilitation: Assistive Technology, Vol. 9 No. 2, pp. 164-172.

Brittain, K., Corner, L., Robinson, L. and Bond, J. (2010), “Ageing in place and technologies of place: The lived experience of people with dementia in changing social, physical and technological environments". Sociology of Health and IIIness, pp. 32(2): 272-87.

Centrale Commissie Mensgebonden Onderzoek (CCMO) (2001), "Gedragswetenschappelijk onderzoek en de WMO: enkele conclusies", Den Haag, The Netherlands

Childress, C. A. and Asamen, J. K. (1998), "The Emerging Relationship of Psychology and the Internet: Proposed Guidelines for Conducting Internet Intervention Research". Ethics and 
Behavior, Vol. 8 No. 1, pp. 19-35.

Conger, D., Rudnick, C., Noland, D., and Newcomer, M. (2019). "Utilization of technology in Alzheimer's disease and mild cognitive impairment (MCl)". Alzheimer's and Dementia: The Journal of the Alzheimer's Association, Vol. 15 No. 7, pp.171-172.

Craig., N and Strivens, E. (2016). "Facing the times: A young onset dementia support group: Facebook TM style. Australasian Journal on Ageing. Vol. 35 No.1, pp. 48-53

DEEP. (2013). Collecting the views of people with dementia: https://www.dementiavoices.org.uk/wp-content/uploads/2013/11/DEEP-GuideCollecting-views.pdf (Acccessed 19 January 2017).

Duff, P. and Dolphin, C. (2007), "Cost-benefit analysis of assistive technology to support independence for people with dementia-Part 2: Results from employing the ENABLE cost-benefit model in practice". Technology and Disability, Vol. 19, No. 2,3, pp.79-90.

European Commission (2015), "Dementia". Public Health, Available at Http://ec.europa.eu/health/major_chronic_diseases/diseases/dementia_en (Accessed: January 19, 2017).

European Parliament (2011), "European Parliament resolution of 19 January 2011 on a European initiative on Alzheimer's disease and other dementias". Available at http://www.europarl.europa.eu/sides/getDoc.do?pubRef=-//EP//TEXT+TA+P7-TA2011-0016+0+DOC+XML+V0//EN (Accessed: January 19, 2017).

Gibson, G., Dickinson, C., Brittain, K. and Robinson, L., (2019). "Personalisation, customisation and bricolage: how people with dementia and their families make assistive technology work for them". Ageing and Society, Vol. 39 No. 11, pp.2502-2519.

Greenhalgh, T., Wherton, J., Sugarhood, P., Hinder, S., Procter, R., and Stones, R. (2013). "What matters to older people with assisted living needs? A phenomenological analysis of the use and non-use of telehealth and telecare", Social Science and Medicine, vol. 93, pp. 8694

Heinonen, K., and Medberg, G. (2018). “Netnography as a tool for understanding customers: implications for service research and practice". Journal of Services Marketing, Vol. 32 
No.6, pp 657-679.

Huber, M., Knottnerus, J.A., Green, L., Van der Horst, H., Jadad, A.R., Kromhout, D., Leonard, B., Lorig, K., Loureiro, M.I., Van der Meer, J.W.M., Schnabel, P., Smith, R., Van Weel, C. and Smid, H. (2011), "How should we define health?" British Medical Journal Vol. 7 No. 26, pp. 343.

INDUCT (2019). "Best Practice Guidance Human Interaction with Technology in Dementia". , available at https://www.dementiainduct.eu/guidance/ (accessed 31 January 2020)

Jamison, J., Sutton, S., Mant, J. and De Simoni, A. (2018), "Online stroke forum as source of data for qualitative research: insights from a comparison with patients' interviews". British Medical Journal Vol. 8 No. 3: e020133.

Keeling, D., Khan, A. and Newholm, T. (2013). "Internet forums and negotiation of healthcare knowledge cultures". Journal of Services Marketing, Vol. 27 No. 1, pp. 59-75.

Kenigsberg, P.-A., Aquino. J.-P, Bérard, A., Brémond, F., Charras, K., Dening, T., Droës, R-M., Gzil, F., Hicks, B., Innes, A., Nguyen, M., Nygård, L., Pino, M., Sacco, G., Salmon, E., Van der Roest, H., Villet, H. Villez, M., Robert, P. and Manera, V. (2017), “Assistive technologies to address capabilities of people with dementia: From research to practice". Dementia, 147130121771409. https://doi.org/10.1177/1471301217714093.

Kozinets, R. V. (2002), "The field behind the screen: Using netnography for marketing research in online communities". Journal of Marketing Research Vol. 39, pp $61-72$.

Kubitschke, L., Müller, S., Gareis, K., Frenzel-Erkert, U., Lull, F., Cullen, K., Delaney, S., Dolphin, C., Wynne, R., and Rauhala, M. (2010), "ICT and Ageing: European study on users, markets and technologies". Final report. Brussels. https://doi.org/10.1111/j.17413729.2010.00637.x.

Lopez, D. (2015), "Little arrangements that matter. Rethinking autonomy-enabling innovations for later life". Technological Forecasting and Social Change.No. 93. pp. 91-101.

Malinowsky, C., Almkvist, O., Kottorp, A. and Nygård, L., (2010). "Ability to manage everyday technology: a comparison of persons with dementia or mild cognitive impairment and older adults without cognitive impairment". Disability and rehabilitation: Assistive 
technology, Vol. 5 No. 6, pp.462-469.

McHugh, J., Wherton, J., Prendergast, D. and Lawlor, B. (2012), "Identifying opportunities for supporting caregivers of persons with dementia through information and communication technology". Gerontechnology, Vol. 10 No. 4, pp. 220-230.

McKechie, V., Barker, C. and Stott, J. (2014), "The effectiveness of an Internet support forum for carers of people with dementia: a pre-post cohort study". Journal of medical internet research. Vol. 16 No. 2, pp. e68-75.

Neven, L. (2010). 'But obviously not for me': robots, laboratories and the defiant identity of elder test users, Sociology of Health and IIIness, vol. 32, no. 2,pp. 335-47

Newman, L., Stoner, C., and Spector, A. (2019). "Social networking sites and the experience of older adult users: a systematic review". Ageing and Society, pp. 1-26.

Nygård, L., Pantzar, M., Uppgard, B., and Kottorp, A. (2012). "Detection of activity limitations in older adults with $\mathrm{MCl}$ or Alzheimer's disease through evaluation of perceived difficulty in use of everyday technology: a replication study". Aging and mental health, Vol. 16 No. 3, pp. 361-371.

Pakkala, H., Presser, K., and Christensen, T. (2012), "Using Google Analytics to measure visitor statistics: The case of food composition websites". International Journal of Information Management, Vol. 3 No. 6, pp. 504-512.

McCabe, L. and Innes, A., (2013). "Supporting safe walking for people with dementia: User participation in the development of new technology". Gerontechnology, Vol. 12 No. 1, pp.4-15.

Meiland, F.J.M., de Boer, M.E., van Hoof, J., van der Leeuw, J., de Witte, L., Blom, M., Karkowski, I., Mulvenna, M.D. and Dröes, R.M., (2012). "Functional Requirements for Assistive Technology for People with Cognitive Impairments and Dementia". In Constructing Ambient Intelligence: Aml 2011 Workshops, Amsterdam, The Netherlands, November 16-18, 2011. Revised Selected Papers (Vol. 277, p. 146). Springer.

Pongsakornrungsilp, S. (2010). "Value co-creation process: Reconciling S-D logic of marketing and consumer culture theory within the co-consuming group". PhD. thesis, Exteter. 
University of Exeter Exeter.

Puig de la Bellacasa (2012). 'Nothing comes without its world': thinking with care, Sociol. Rev. Vol. 60 No. 2 pp. 197-216.

Rahimi M. and Vaughn-Cooke M. (2007) "Information architecture for an Alzheimer's communication monitoring system (ACMS)". Gerontechnology Vol. 6 pp. 42-55.

Rialle, V., Ollivet, C., Guigui, C., and Hervé, C. (2009), "What do family caregivers of Alzheimer's disease patients desire in smart home technologies? Contrasted results of a wide survey". Methods of Information in Medicine, Vol. 1 No. 1, pp. 63-9.

Robinson, L., Brittain, K., Lindsay, S., Jackson, D., and Olivier, P. (2009), “Keeping In Touch Everyday (KITE) project: developing assistive technologies with people with dementia and their carers to promote independence". International Psychogeriatrics /IPA, Vol. 21 No. 3, pp. 494-502.

Robinson, L., Hutchings, D., Corner, L., Finch, T., Hughes, J., Brittain, K. and Bond, J. (2007), "Balancing rights and risks: Conflicting perspectives in the management of wandering in dementia". Health, Risk and Society, Vol. 9 No. 4, pp. 389-406.

Scholz, N. (2016), "Need for action on dementia recalled. Brussels-Luxembourg". Available at http://www.europarl.europa.eu/RegData/etudes/BRIE/2016/577959/EPRS_BRI(2016)5 77959_EN.pdf (Accessed: May 08, 2017).

Steffes, E. M. and Burgee, L. E. (2009), "Social ties and online word of mouth". Internet Research, Vol. 19 No. 1, pp. 42-59.

Talbot, C. V., O'Dwyer, S. T., Clare, L., Heaton, J., and Anderson, J. (2020). "How people with dementia use twitter: A qualitative analysis". Computers in Human Behavior, Vol. 102, pp. 112-119.

Taylor, S.J. and Bogdan, R. ( 1984 ), Introduction to Qualitative Research Methods: The Search for Meanings. New York: John Wiley and Sons .

Thomas, B. (2017). "Whose Story Is It Anyway? Following Everyday Accounts of Living with Dementia on Social Media". Style, Vol. 51 No. 3, pp. 357-373.

Van Hoof, J., Kort, H.S.M., Van Waarde, H. and Blom, M.M. (2010), "Environmental 
interventions and the design of homes for older adults with dementia: an overview". American Journal of Alzheimer's Disease and Other Dementias, Vol. 25 No. 3, pp. 202-32.

Vermeer Y., Higgs P., Charlesworth G. (2019c) "Surveillance Technology in Dementia Care: Implicit Assumptions and Unresolved Tensions". In: Brankaert R., IJsselsteijn W. (eds) Dementia Lab 2019. Making Design Work: Engaging with Dementia in Context. D-Lab 2019. Communications in Computer and Information Science, vol 1117. Springer, Cham. pp. $101-113$

Vermeer, Y., Higgs, P. and Charlesworth, G. (2019b), "What do we require from surveillance technology: A review of the needs of people with dementia and informal caregivers". Journal of Rehabilitation and Assistive Technologies Engineering, 6, p.2055668319869517.

Vermeer, Y., Higgs, P. and Charlesworth, G. (2019c), "Marketing of surveillance technology in three ageing countries". Quality in Ageing and Older Adults. Vol. 20 No. 1, pp. 20-33

Wallcook, S., Nygård, L., Kottorp, A. and Malinowsky, C., (2019). "The use of everyday information communication technologies in the lives of older adults living with and without dementia in Sweden". Assistive Technology, pp.1-8. Https://doi.org/10.1080/10400435.2019.1644685

Wan, L., Müller, C., Randall, D. and Wulf, V. (2016), “Design of A GPS Monitoring System for Dementia Care and its Challenges in Academia-Industry Project". ACM Transactions on Computer-Human Interaction, Vol. 23. No. 5, pp. 1-36.

Wimo, A., Guerchet, M., Ali, G.C., Wu, Y.T., Prina, A. M., Winblad, B., Jönsson, L., Liu, Z. and Prince, M. (2017), "The worldwide costs of dementia 2015 and comparisons with 2010". Alzheimer's and Dementia, Vol. 13 No. 1, pp. 1-7.

World Health Organization (2012), "Dementia a Public Health Priority". Available at https://www.who.int/mental_health/publications/dementia_report_2012/en/ (Accessed: January 19, 2017).

Xun, J. and Reynolds, J. (2010), "Applying netnography to market research: The case of the online forum". Journal of Targeting, Measurement and Analysis for Marketing, Vol. 18 No. 1, pp. 17-31. 